\title{
Corruption as Social Exchange
}

Edward J. Lawler

Cornell University

\author{
Lena Hipp \\ Berlin Social Science Center (WZB)
}

Advances in Group Processes (2010), 27, 269-296.

The authors thank Shane Thye and Jeongkoo Yoon for helpful comments. 


\begin{abstract}
This chapter applies social exchange theory to corruption. If two parties exhibit corrupt behaviors, secrecy becomes a new joint good, making the two parties more dependent on each other (an increase in total power). Since no external enforcement mechanisms are available in illicit exchanges, the initial reciprocal exchange pattern shifts toward negotiated or productive forms of exchange. Such forms of exchange, however, tend to leave traces, either because the amount of traded resources increases or the contingencies between the behaviors become more visible to the outside. Using the larger network structure, in which corrupt exchanges are embedded, to deal with the problem of detection also is Janus-faced. Adding more ties to the exchange increases either the competition between several potential exchanges partners (exclusively connected network) or the risk of nonreciprocity and whistle blowing (positively connected network). By showing that illicit relations are inherently unstable, we specify some of the scope conditions of social exchange theory.
\end{abstract}


Corruption remains a core governance problem around the world. It undermines public trust in the democratic process and damages individual lives.

The annual report of Transparency International, the worldwide nongovernment organization intended to fight corruption, identifies four important facts about corruption: (1) Corruption is widespread; (2) corruption occurs in politics as well as in private business; (3) corruption threatens democratic processes; and (4) corruption causes great costs to consumers and citizens. Its immense negative consequences have made corruption a relevant field of study for economists and political scientists (Della Porta \& Meny, 1997; Della Porta \& RoseAckerman, 2002; Lambsdorff, Taube, \& Schramm, 2005). Corruption, moreover, is a social phenomenon of generic interest to sociologists (e.g., Ashforth \& Anand, 2003; Granovetter, 2007).

Several questions can frame or provide the focus for an analysis of corruption. Why do people engage in corruption? How can corrupt relationships be stable given that there are no external enforcement mechanisms? And, given this stability, why is it that corrupt exchanges are ultimately revealed? A common and convincing answer to the first question is that the temptations to engage in corrupt behaviors are too great to be resisted, especially in the absence of effective control and monitoring (e.g., Klitgaard, 1988). The second and third question, however, have received less attention in the academic research on corruption (Lambsdorff, 2002a, 2002b; Lambsdorff, et al., 2005 are notable exceptions). To answer these questions, this chapter theorizes corruption as a special form of social exchange (Emerson, 1972a, 1972b; Lawler, 2006; Molm \& Cook, 1995) and analyzes the internal dynamics of corrupt relationships. Recent social exchange theory and research has made significant strides in understanding how social exchanges generate social relations. Social structures generate internal, endogenous 
dynamics that create relational ties by (a) reducing uncertainty and risk (Kollock, 1994; Molm, 1994; Molm, Peterson, \& Takahashi, 1999) and (b) promoting positive emotions and affective sentiments about the social relation (Lawler \& Yoon, 1996, 1998). We show how these findings apply to corrupt exchanges but suggest that relational ties in the context of corruption have the opposite effect, that is, they destabilize relationships. This has implications for illicit exchanges more generally, whether they involve corruption or not.

A corrupt relation is conceptualized as an ongoing relational tie involving two or more people - A and B-who exchange valued resources or goods that are not their own. Thereby at least one of them misuses “entrusted power for private gain” (Transparency International, 2008). This definition implies that at least one of the parties has an official position or role with power legitimized in a larger normative framework; and that party misuses the power granted to generate private benefits. Three dimensions distinguish corrupt exchanges from other types of social exchanges: (a) The exchange of benefits is illicit or illegitimate, given prevailing norms. (b) Once it occurs, parties have a joint interest in secrecy. (c) Finally, it generates negative externalities for third parties (i.e., imposes costs on), such as shareholders, constituents, or publics. Corrupt exchanges are involved when government officials have preferentially awarded contracts and received gifts or kickbacks, when financial analysts have exchanged insider, proprietary information about stocks to each other, and when universities have steered students seeking loans to select companies and received a share of profits from those loans. No organization is exempt from the potential for corruption involving an illegitimate exchange of benefits, services, or privileges.

It is important to stress that this chapter focuses on the relational effects of corrupt exchanges rather than the sources or causes of corruption. We examine corruption emerging out 
of ongoing relationships rather than from random encounters between strangers or acquaintances. What issues or problems does a corrupt exchange pose for actors? How do they address or solve these problems? How do their efforts to solve problems associated with a corrupt exchange bear on the stability or instability of their larger relational tie? By posing these questions, this chapter is both an application of social exchange theory to corruption as a particular form of social exchange and an effort to extend the theory to social exchanges that are illicit, create a demand for secrecy, and have negative externalities for third parties.

Our overall message is that corrupt relations contain the seeds of their own destruction. Corruption destabilizes legitimized relationships insofar as such exchanges unleash internal problems that actors solve by making themselves even more vulnerable to each other and to outsiders. Corrupt exchanges make people more dependent on each other while simultaneously balancing or equalizing their power, which should promote greater stability of the relation (Lawler, Thye, \& Yoon, 2008; Lawler \& Yoon, 1996). However, the new joint good (in the form of secrecy) produced by corrupt behaviors threatens this stability because of problems of enforcement and detection. Changes in power help the parties to corruption to solve the enforcement problem, by making their mutual interests and shared task more salient, but in doing so they are prone to move toward forms of exchange that entail more risk of detection. These risks of detection vary with network configurations, in particular with how the actors are connected to others in the network.

The chapter is organized into four sections. The first section reviews existing approaches to corruption. The second section introduces the social exchange framework. It describes the social context of corrupt exchanges and their fundamental problems of enforcement and detection. The third section elaborates on social exchange theory in more detail and analyzes (a) 
how corrupt exchanges change the power dependence relationship of the actors, (b) why corrupt relationships shift to forms of exchange that are riskier and more likely to be detected, and (c) how different network configurations exacerbate and mitigate risks of detection.

\section{EXISTING APPROACHES TO CORRUPTION}

The vast majority of research on corruption aims to identify the main causes of corruption and the conditions under which it is likely to occur. The larger purpose is to develop policies for reducing or preventing corruption (see Donatella Della Porta \& Rose-Ackerman, 2002; Donatella Della Porta \& Vannucci, 1999, 2005; Klitgaard, 1988; Rose-Ackerman, 1999). There is a strong rationale for this applied focus. Corruption is generally perceived as a key threat to effective government and economic development (e.g., Klitgaard, 1988; Transparency International, 2008). Corruption has damaging effects on the modernization of underdeveloped nations, the costs of public projects, and the moral or ethical fabric of communities in which corrupt practices become standard, institutional patterns (e.g., Azfar, Lee, \& Swamy, 2001; Rose-Ackerman, 1999; Transparency International, 2008). Overall, there has been little effort to develop theories of corruption or, in light of its relational property, to interpret corruption in sociological terms. Granovetter’s (2007) recent work on corruption is a notable exception.

There are two primary approaches in previous work on corruption: (1) Economic (rational choice) approaches ask why individuals choose to engage in corrupt practices and target the incentives for one party, for example, a government official or an organizational representative, to accept bribes and for another party, for example, a client, a customers, or an ally to offer them. Principal-agent theory (Klitgaard, 1988) emphasizes the tie between the 
principal, that is, the damaged third party, and the agent, that is, the party engaging in corrupt behaviors. The newer transaction costs approach to corruption, in contrast, emphasizes the tie between the parties engaging in corrupt behaviors, for example, the briber and the bribed (Lambsdorff 2002a, 2002b; Lambsdorff et al., 2005). (2) Sociological (institutional) approaches ask how corrupt practices become standard, taken-for-granted “ways of doing business,” for example, what norms or normative conditions promote or fail to prevent corruption. The emphasis is on the normative-institutional conditions under which professional or job-related effectiveness or success may promote or even require corrupt practices, despite a larger normative/legal framework casting them as inappropriate and illegitimate (e.g., Ashforth \& Anand, 2003; Granovetter, 2007; Heidenheimer \& Johnston, 2001). Below we briefly elaborate these two approaches.

Principal-agent theory from economics is the dominant theoretical approach in existing literature on corruption. Its emphasis is the incentives of individuals (agents or officials) to engage in corrupt behaviors and the social-economic conditions that underlie these incentives. The “agents” of principal-agent theory are responsible and accountable to principals, but principals have difficulty overseeing the behaviors of agents. They have latitude and freedom to “cut deals” with those they serve without principals being aware of those private deals. Klitgaard (1988) argues that public- sector corruption is a result of public agents having monopoly power with high levels of discretion and little oversight. Using transaction cost economics, Lambsdorff and colleagues (2002a, 2002b, 2005) added a relational component to the analysis of corrupt relationships. ${ }^{1}$ Engaging in corrupt behaviors is only "worthwhile" when transaction costs of the relationship, that is, the costs of ensuring the desired outcomes and secrecy are lower than the expected gains. From these points of view, prevention efforts should be directed at changing the 
cost/benefit calculus of individual agents. This typically involves an enhancement of oversight and accountability by principals and the encouragement of whistle blowing.

Norms, values, and the prescribed scripts of "how things are done” are the cornerstone in sociological and cultural explanations of corruption (Ashforth \& Anand, 2003; Granovetter, 2007; Husted, 1999). The idea is that definitions and perceptions of what is a corrupt versus a legitimate behavior are socially constructed and therefore vary across time and place. Some behaviors may be common, tolerated practices in one context but considered corrupt in another. Paying a fee to a public official for receiving preferential treatment or asking a friend to give a job off to a relative despite his or her lack of qualification and skills, for example, may be viewed a legitimate thing to do in one country or group - or even an act of appreciation and loyalty while it would be socially unacceptable and legally prosecuted in another. Sociological and cultural approaches to corruption come out of empirical findings rather than from a unified theoretical framework (Banfield, 1958; Cohen, Pant, \& Sharp, 1996; Husted, 1999). From this approach, prevention efforts should be directed toward the top leadership levels of an organization or a political elite, such that changes in values, norms, and expectations trickle down the organizational hierarchy of a public and private sector organizations.

Economic and sociological approaches have distinct but not necessarily contradictory ideas about corruption. Economic (rational choice) theories focus on the individual-level incentive structure shaping the expected utility that agents ascribe to corrupt versus noncorrupt behaviors, whereas sociological (institutional) theories tend to emphasize how and why corrupt behaviors become widespread, standard practices. Rational choice theories may be well-suited to explain how corrupt behaviors start, whereas institutional theories may be well-suited to understand the implications of repetitive patterns of corruption becoming routine and taken for 
granted. An important difference is that in the former, actors make a choice to be corrupt based on cost/benefit calculations, whereas in the latter actors essentially "lack choice” because of institutional conditions and informal cultural expectations. Social exchange theory can incorporate elements of both rational choice and institutional approaches to corruption in the sense that it is an incentive-oriented theory, explicitly pointing to relational and, by implication, institutional effects of repeated patterns of interaction or exchange (Lawler, Thye, \& Yoon, 2009, chap. 10). Recent social exchange theorizing is a foundation for elaborating the relational dimensions of corruption and analyzing the sources of stability and instability in relations involving corrupt exchange.

\section{THE SOCIAL CONTEXT OF CORRUPTION}

A key tenet of social exchange theory is that people form and maintain relations with persons who they are dependent on for valued rewards or outcomes, and moreover that repeated exchanges are integral to social compared to economic exchanges (Emerson, 1972a, 1972b). Social exchange theory is built on the assumption that people respond to or seek increases in their outcomes, rewards, or profits, but that this need does not entail profit maximization (Molm \& Cook, 1995). People ostensibly maintain an existing relational tie as long as it remains rewarding or beneficial, even though there may be better exchange opportunities available outside of the existing tie. They may stay in a relationship because of intangible or intrinsic benefits, because they face less uncertainty and risk by remaining, or because the relational tie itself has expressive value. 
Using social exchange theory, we construe corruption as a repeated pattern of socially embedded exchanges, that is, corruption occurs within an ongoing network of social ties between parties. Close professional relationships may spawn occasional corrupt exchanges that over time expand in scope or become more common. The implication is that whereas corruption often involves an economic exchange (e.g., bribes for contracts), it is social exchange if there is an ongoing relational tie. Economic approaches to corruption tend to miss or downplay this socialrelational dimension of corruption. In many settings, corrupt practices appear to develop in ongoing, normatively legitimate relationships within which two or more parties provide each other valued outcomes over time. Corrupt exchanges occur and are sustained if they affirm an ongoing legitimate relation and that larger tie helps to secure or guarantee the secrecy of the corrupt exchange.

Consider an example. In 1989, Daniel arap Moi, then President of the Republic of Kenya, received a series of "personal donations” in connection with the construction of duty-free complexes in the airports in Nairoibi and Mombassa from the "World Duty Free Company." At the International Centre for Settlement of Investment Disputes in June 2000, Mr. Nasir Ibrahim Ali, the CEO of Word Duty Free Company testifies: “As a leading businessman in Dubai, I met in normal business circles, one Rashid Sajjad, a Kenyan, who would come to Dubai frequently in order to buy goods for export to Kenya for his company [...] From my discussions with Sajjad, I came to understand that he was politically and powerfully connected in the Kenya Government. Wishing to diversify my business from perfumes into the duty-free market, I raised my interest with Sajjad and asked his advice on arranging the necessary licenses and authorization for the establishment of duty free complexes in Nairobi and Mombassa airports. Sajjad informed me that he would arrange meetings for me with the relevant officials in Kenya. [...] Sajjad informed me 
that although my concept for establishing duty-free complexes at Nairobi and Mombassa airports to an international standard would require heavy investment, which I believed would be for the national benefit of Kenya, protocol in Kenya required that I should in addition make a 'personal donation'. I was given to believe, that this was payment for doing business with the Government of Kenya. [. ] I felt uncomfortable with the idea of handing over this "personal donation” which appeared to me to be a bribe. However, this was the President, and I was given to understand that it was lawful and that I didn’t have a choice if I wanted the investment contract” (TDM, 2006, p. 37).

This quotation illustrates several points. First, Mr. Ali essentially slid down a "slippery slope” in the context of an existing, ongoing relationship in which legitimate exchanges took place. Some approaches assume that corrupt exchanges stem from pure, unbridled opportunism, but this is not necessarily the case when there is an ongoing, legitimate relation or association (see Ashforth, Gioia, Robinson, \& Trevino, 2008, for a related discussion). People can inadvertently cross a line and not recognize it until afterwards. Second, those in an ongoing relationship are dependent on each other for valued social or economic goods, and thus, they have an incentive to sustain if not nurture their relationship, especially when the "shadow of the future” is long or indefinite. This is why Mr. Ali responded to Mr. Saijad’s requests. Third, by engaging in a corrupt exchange, the relationship of the parties changes in a significant way. Over time, Mr. Sajjad became more explicit in his requests for bribes, as Mr. Ali further describes in his testimony.

"During the negotiations of the investment agreement, I was frequently travelling backwards and forwards between Dubai and Kenya. During this time I received several requests for gifts to bring for officials in the Kenyan Government. I was not given any money in return 
for these items and it appeared to me that it was expected that I would bring what they requested. I received a request by fax from Sajjad on 2 May 1989 with a shopping list for watches [...]. On 3 May 1989 I received a telex from Sajjad requesting a gift of the latest model Polaroid camera” (TDM, 2006, p. 38).

These requests for more and more gifts show how corrupt exchanges in the context of a legitimate relation can evolve in subtle ways. Keeping the exchange hidden from others to combat detection is a new dimension in the relationship that needs to be ensured partners. Secrecy emerges as a new joint good, exerting additional pressure on the ongoing relationship. Moreover, the example illustrates that those who engage in a corrupt exchange face two fundamental problems: how to enforce or guarantee that the exchange occurs as agreed to, and how to avoid detection by outsiders to the exchange relation.

The enforcement problem of corrupt exchanges stems from the fact that when these exchanges occur, there are no standard external enforcement mechanisms (e.g., judicial institutions) as there are for legitimate exchanges (Lambsdorff 2002a, 2002b). Neither party has a legitimate avenue of recourse if the other fails to live up to the implicit or explicit bargain or understanding. As a result, corrupt parties tend to develop their own enforcement mechanisms outside of legitimate channels but internal to the relationship (e.g., development of a close, personal tie, threats of violence).

The detection problem complements the enforcement problem, because what is at issue is not just whether the exchange occurs as agreed to, but also whether each party will work to maintain the secrecy of their corrupt exchanges. In corrupt exchanges, each party has an incentive to collaborate on its continual reproduction and reasons to worry whether the other will do likewise. Given that the tie between two corrupt exchange partners is embedded in a larger 
network, information can flow to others or those others may notice patterns that raise suspicion. Thus, theoretically, the confluence of enforcement and detection problems makes corrupt exchanges difficult to sustain, unless they are nested in a larger, ongoing relationship that provide parties with the capacity to solve these problems internally and endogenously. A larger, ongoing relationship helps to guarantee and sustain corrupt practices to the degree that it fosters high interpersonal trust, valued legitimate rewards that can be withheld in the future, and/or credible threats of harm. Yet, internal solutions, even in the context of socially embedded ties, may be unstable and fragile over time. Ideas from social exchange theory suggest this.

Social exchange theory and research specifies several internal mechanisms whereby people may develop the capacity to mutually influence and control each other: trust conceived as “encapsulated interest” (Cook, Hardin, \& Levi, 2005); relational cohesion or the sense of a unifying relational tie (Lawler \& Yoon, 1996); or positive affective sentiments toward each other or that relational tie (Lawler, 2001; Molm, Schaefer, \& Collett, 2009). We will elaborate each of these mechanisms in the following sections. The question guiding our argument is: How well can such internal solutions to enforcement and detection problems hold in the case of corrupt exchanges that demand or require secrecy?

We theorize that parties to a legitimate relation who engage in an illicit exchange face a dilemma they cannot solve. The dilemma is that solutions to the enforcement and detection problems tend to operate at cross-purposes. If in solving the enforcement problem, parties strengthen interpersonal trust by developing a closer social tie, this could raise suspicion and make their corrupt behaviors more vulnerable to detection by outsiders. If the detection problem is solved by collaborating more explicitly to maintain secrecy, the actors become even more dependent on each other's trustworthiness and multiple layers of secrecy then become critical. In 
general, mitigating enforcement problems tend to enhance the detection problems and vice versa. This has implications for how and why internal, endogenous effects of corrupt exchanges create the "seeds of relational destruction."

\section{THE SOCIAL EXCHANGE FRAMEWORK}

Social exchange theory interconnects social structures, transactions between people, and relational effects or consequences. Structures of dependence and interdependence are the basis for incentives that people have to interact and exchange with some, but not others in their network; transactions are the efforts of those who are interdependent on each other to exchange valued benefits or goods; and relations are the result of repetitive transactions (exchanges) among the same people over time (Emerson, 1981; Lawler \& Thye, 2006). From the theory, repetitive transactions are likely to persist as long as social structures entail stable incentives for two actors to interact; yet, relations that form under such conditions also can produce changes in the structure. This is especially so, if the relations where the most frequent interactions occur are set off from other less frequently enacted ties in the network, generating "pockets of cohesion” in the network (see Lawler \& Yoon, 1998). Such effects should be common, if not exaggerated, in the case of corrupt exchanges, because joint interests in secrecy emerge with corrupt behaviors and make the relational tie even more distinctive from other ties.

The development of exchange relations - that is, repeated, regularized patterns of interaction - has been tied to three fundamental conditions: (1) the power and dependence relations between the actors, that is, whether they have equal or unequal power (Lawler \& Yoon, 1996); (2) the interconnections of the actors' behaviors in the transferring benefits to each other, 
that is, whether the exchange is negotiated, reciprocal, productive, or generalized (Emerson, 1981; Lawler, 2001; Molm, 1994); and (3) the shape of the larger network, that is, how the relational ties within it are interconnected (Emerson, 1972b; Molm \& Cook, 1995; Willer, 1999). Applied to corrupt exchanges, each of these conditions poses a central question: Whether and how corrupt exchanges shift the power relation of the people involved? Whether and how over time corrupt exchanges lead people to coordinate and connect their individual actions in different ways? Whether and how corrupt exchanges affect the prospects that others in the network will become aware of focal actors' corruption? The following sections address each of these questions.

\section{Power and Dependence in Corrupt Exchanges}

The social exchange approach to power assumes that power is a structurally based potential that is relational in form and grounded in interdependencies. An actor's (A) power over another (B) is based on the dependence of B on A (Emerson, 1972b). The amount of A's power is determined by (1) the value B places on the outcomes or rewards provided by A, and (2) the availability of alternative As from whom those outcomes or rewards can be acquired by B. Applied to a corruption context, corruption tends to occur when A has exclusive control over a resource valued by one or many Bs and can command a high price for illicit services - for example, a procurement officer choosing an outside contractor among many who could do the job (see Klitgaard, 1988). Corruption may also occur in a context where there are many As and Bs available, and pairs of actors form relational ties and engage in illicit exchanges through which the actors gain an advantage vis-d- vis others - for example, trading insider information 
among financial analysts. By analyzing the dependencies and interdependencies in corrupt relations, new light can be shed on the problems of enforcement and detection explained earlier.

A central implication of power dependence theory is that power is a nonzero sum phenomenon (Bacharach \& Lawler, 1981; Lawler, 1992; Molm, 1987). Each person’s power can increase or decrease simultaneously, because mutual dependencies can and do grow or decline in ongoing relationships. An increase in one party's power does not by definition imply a decrease in another's power. This has led to a distinction between the "total power" in a relationship, that is, the sum or average power across actors (Bacharach \& Lawler, 1998; Molm, 1987), and the "relative power" in that relationship, that is, the difference in power among the actors (Bacharach \& Lawler, 1981; Lawler \& Yoon, 1996; Molm, 1987). Total power can vary with relative power constant, just as relative power can vary within a given level of total power. Corrupt exchanges can change the power relationship along either or both of these dimensions, for example, by increasing the mutual dependence (total power) of the actors or by making them more or less equal in power.

Power dependence theory helps to explain why many developing countries face persistent patterns of corruption in their public agencies. Here, private actors (e.g., individuals or companies seeking contracts) are often highly dependent on poorly paid, low-status government agents for valued resources and outcomes, but these government officials have substantial control over the allocation and distribution of valued resources (Donatella Della Porta \& Vannucci, 1999; Klitgaard, 1988; Rose-Ackerman, 1999). Even though the agent (A) may occupy a small niche in a large bureaucracy and have relatively little status or influence within the organization or society, he or she may have significant power vis-a-vis contractors in bidding for work. The agent (A) has many potential contractors (from whom he can potentially accept 
bribes or kickbacks); B has few public officials (perhaps only one) with access to the contracts desired. The agent's exclusive access to valued government contracts, combined with high discretion in allotting them, gives A significant power over B because B is highly dependent on A. In exchange network terms, this is a "strong power branch" network (Willer, 1999), where a central actor has resources valued by many others who do not have resources of similar value to the central actor or to each other. Such a branch network captures the main structural condition underlying Klitgaard's (1988, p. 75) argument that corruption of public agents is a function of monopoly power of a resource, along with wide discretion to use that resource and a lack of accountability. The principal-agent explanation is that together these three conditions maximize information asymmetries between the agent and principal; the principal-agent tie accounts for the corrupt agent-contractor tie. Social exchange theory shifts the interpretive focus to the agentcontractor relation and suggests how corrupt exchanges change that relation. ${ }^{2}$

Research on social exchange indicates that increases in total power (mutual dependence) or equal, compared to unequal, power generate more cohesion in and commitment to an exchange relation (Lawler \& Yoon, 1993, 1996, 1998; Thye, Yoon, \& Lawler, 2002). Mutual dependencies (total power) generate stronger incentives for collaboration, and equal power makes exchanges easier by avoiding equity and justice issues that tend to occur in relations of unequal power. These general effects of “total power" and "relative power” help to disentangle the stabilizing and de-stabilizing features of a corrupt exchange. If corruption increases mutual dependence (total power) in the relationship, it provides corrupt actors with additional incentives to collaborate in the production of new joint goods. If corruption has a balancing (equalizing) effect on the power relationship, it makes it possible for corrupt actors to interact as full partners. Both of these conditions should promote trust, defined as "encapsulated interests," that is, the 
belief that each person's future behavior will take the other's interests into account (Cook et al., 2005).

The increase in total power is manifest in the "fact" that once two people with an ongoing relational tie engage in a corrupt exchange, they each become more dependent, each on the other. This signals a qualitative change in the relationship due to secrecy, becoming a new joint good that is salient, highly valued, and necessary to avoid the costs of detection. Each has a strong interest in continuing to produce and re-produce this joint good, and each knows that the other knows they are highly dependent on each other in this respect. Moreover, each understands that is it truly a joint good that can only be generated, collectively and collaboratively. However, given a lack of certainty, they are likely to watch for or create opportunities to affirm each other's intent to continue to cooperate and maintain secrecy. This may be done by engaging in new varieties of corruption that presume and test the trust of each in the other and by developing a closer personal relationship.

Parties to corruption are also likely to make inferences about each other’s competence and willingness to maintain secrecy. If $\mathrm{B}$ is more careless than $\mathrm{A}$ or has close ties to other Bs who may suspect their corruption, this is a threat to the ongoing relationship between A and B. The upshot is that total power strengthens the joint interests of the corrupt actors, presents them with a new joint task (maintaining secrecy), and motivates them to cooperate in new ways to demonstrate their reliability and commitment to each other. Such changes, however, foster new vulnerabilities for each.

One of the important findings from research on commitment in exchange relations is that relational ties are more cohesive if the jointly produced benefits are associated with positive emotions (i.e., energy or excitement as well as pleasure or satisfaction) and more frequent 
interactions or exchange (i.e., success at generating benefits for each actor). Those relations with higher total power or mutual dependence should generate more frequent interaction and exchange, and this repetition fosters more relational cohesion. The broad implication is that, all other things equal, corrupt exchanges should produce closer ties in which the frequency and domains of interaction and exchange expand. A purely professional tie may develop a personal dimension through more regular contacts outside of the professional setting, for example, informal meetings after work, helping each other with personal issues, getting to know each other's families, and so forth. The relational tie thereby becomes multidimensional and, potentially, more visible to or detectable by outsiders.

The underlying basis for the upward shift in total power - the need or demand for secrecy - also should have a power-balancing effect (Emerson, 1972b). In his classic statement of social exchange theory, Emerson (1972b) argued that exchange relations tend toward balance. Specifically, if an actor (A) has more power than another actor (B) within a relationship, A will use that power to extract more benefits or resources from B, which ultimately will lead toward a more balanced relationship. The power-balancing effect can occur either because A, the party that uses power, becomes more dependent on $\mathrm{B}$, that is, those they receive the increasing benefits from, or those from whom they extract resources (B) become less dependent on A. We hypothesize that in the case of corruption, the former is more likely than the latter, that is, an agent (A) with more power becomes more dependent on the other (B) as a result of a corrupt exchange. The importance of power-balancing effects may be contingent on whether and to what degree the initial power relations among corrupt actors are unequal. We conjecture that the total power effects of corrupt exchanges are most fundamental and pervasive; power balancing effects are important especially in highly unequal power relations. 
To summarize, we propose that the insights of power-dependence theory are fruitful to understand how corrupt exchanges are sustained and how they change over time. Our main argument is captured by the following propositions on the impact of corrupt exchanges on power dependence relations between two actors:

1. Corrupt exchanges in an ongoing relation increase the mutual dependence (total power) of parties to that relationship insofar as it arouses a shared interest in secrecy (a new joint good).

2. A shared interest in secrecy promotes more frequent interactions within which actors affirm their intent to maintain secrecy and demonstrate their capacity to do so (competence).

3. Given 1 and 2, corrupt exchanges increase the relational cohesion of a corrupt social tie by further setting it off from other relational ties (pocket of cohesion effect).

4. When the initial relationship among corrupt actors is unequal, the total power effects are enhanced by concomitant shifts in power toward greater equality (power balancing effects).

Given the above, we assert that collaborative responses to shared interests in secrecy may increase the likelihood that corrupt exchanges are detected over time. Why does a closer tie, based on high mutual dependence, not have the reverse effect - namely, protect the corrupt actors from detection by others? The reason is that collaboration responses to the secrecy problem shift the underlying form of exchange. To understand this, we apply standard forms of social exchange to corruption in the next section (Emerson, 1972b, 1981; Lawler, 2001; Molm, 2003b). 


\section{Forms of Corrupt Exchange}

Corrupt relations involve one of three forms of social exchange: reciprocal, negotiated, and productive. ${ }^{3}$ Reciprocal exchange involves acts of giving by each actor, separated in time and undertaken without explicit expectations of when and even whether the favors will be reciprocated (Emerson, 1972b; Lawler, 2001; Molm, 1994, 2003a, 2003b). Watering plants for neighbors when they are away or reciprocating dinner invitations are examples of everyday forms of reciprocal exchange, as is the case of a politician who does a favor to a major campaign contributor. Negotiated exchanges, in contrast, involve the explicit, agreed-upon barter of valued benefits. The prototype is two actors with diverging interests, such as a management and a union representative, who exchange offers and counteroffers to reach mutually acceptable agreements or accords. Here the connection between the giving behaviors of each is known and understood to them, that is, the terms of the exchange are explicit. Whether bribes involve negotiated or reciprocal exchange depends on how close and explicit is the connection between giving behaviors. Productive exchange entails a joint or collective product that actors have an incentive to produce and reproduce. Actors essentially work on a common project that neither can do alone and they succeed only if each does their part, as it is the case for scholars jointly writing an article, for example. Racketeering forms of corruption tend to have elements of productive exchange, along with reciprocal and negotiated forms.

Reciprocal exchange is the most basic form of corruption because it is the easiest and most straightforward way for parties to create a disconnect between their giving behaviors. The disconnection of A's and B's corrupt behaviors is maximized if the giving behaviors are separated in time, involve an implicit or informal understanding, and do not necessarily fall 
within the same reward or value domain. ${ }^{4}$ Through reciprocal exchange, actors are most able to conceal and blur the contingencies between their corrupt behaviors. However, while reciprocal exchange is optimal for parties to corruption, it is unstable because of a significant trust problem; actors cannot be sure that the other will reciprocate benefits or do so in a timely way. In Molm’s (2003a) terms this is the "risk of non-reciprocity," reflecting the enforcement problem endemic to such types of exchange, legitimate or corrupt. Corrupt reciprocal exchanges accentuate the risk of nonreciprocity and therefore the enforcement problem, in part because the necessity of secrecy adds another layer of exposure to risk. Thus, corrupt exchanges foster a multilayered trust problem: Each looks for assurance that the other will reciprocate, but also that the other can and will maintain the secrecy of their transaction. The above-described example of the bribes paid by World Duty Free Company Limited to the former Kenyan president and government officials illustrates this problem. The link between the duty free complexes in the Kenyan airports and the payment of "personal donations” needed to be concealed from the outside, while it was not yet certain that the actual construction, maintenance, and operation of the duty free shops would occur.

Based on recent social exchange theorizing, there are several ways that actors can address the enforcement problems internally, that is, within the confines of their relationship. We emphasize two that entail a shift in the form of the exchange, that is, the connections between their giving behaviors: (1) Develop explicit, mutually acknowledged terms of exchange, which involves a shift from reciprocal to negotiated exchange; (2) collaborate in new ways that take advantage of their shared interest in secrecy and affirm or demonstrate their commitment to their relationship, which involves a shift from reciprocal to productive exchange. These movements away from a purely reciprocal form of exchange to negotiated or productive exchange can occur 
in any ongoing legitimate relationship, but, importantly, corrupt exchanges make such shifts likely as mechanisms for dealing internally with the enforcement problems associated with reciprocal forms of illicit exchange. Each shift in exchange form may help to assure actors that the exchange will occur as expected and each can rely on the other to maintain secrecy.

By shifting from reciprocal to negotiated forms of exchange, actors develop a better understanding of what they will do for each other and they can more effectively coordinate the value and frequency of benefits provided. The actors identify the terms of the exchange, make clear each actor's expectations of the other, and reduce miscommunication. This is a highly effective way to deal with problems posed by the risks of nonreciprocity inherent in reciprocal exchange. A private contractor is not likely to provide a significant gift (bribe) to a public official unless the contractor believes this will result in a contract; nor is the corrupt public official likely to favor a particular contractor unless the official is relatively sure that a bribe or kickback will be forthcoming. Illegitimate or illicit exchanges increase the risks of nonreciprocity while giving actors few options for handling these risks. A larger, ongoing, legitimate relationship may require less explicit understandings about what each does for the other, but purely reciprocal corrupt exchanges are still likely to be unstable over time without more explicitness about who does what and when. The main point is that an endogenous problem (enforcement or the risk of nonreciprocity) encourages a shift toward negotiated exchange; yet making the terms more explicit enhances and complicates the problem of secrecy. Negotiated forms of corrupt exchanges are likely to involve revealing behavioral indicators of the contingencies between what each does for the other, and as a result, the actors become more vulnerable to detection by outsiders and also to defection by each other. ${ }^{5}$ 
In productive exchange, the interests between parties are aligned, meaning that the joint benefits from “'teamwork” are greatest, as long as each continues to invest the necessary time, effort, or resources. Coordinating behaviors to maintain secrecy is likely to involve productive exchange. In fact, the secrecy problem sets the stage for an expansion of the corrupt practices or exchanges because it makes actors more aware of their capacity to work together. With productive exchanges, there are single joint products and the individual contributions to them are not always explicit or clear, as in negotiated exchange. In the productive form, exchanges are essentially person-to-group and group-to-person (Lawler, 2001). Racketeering, a particular form of corruption, tends to have elements of a productive exchange. Only through tight collaboration fixing prices, paying bribes, and sometimes even using violence, for example, have garbage cartels in New York and New Jersey ensured gigantic gains for trash collection.

An important feature of productive exchange is that it generates relational or group ties and, thereby, more stability, cohesion, or solidarity (Lawler, 2001; Lawler et al., 2008, 2009). In the case of corruption, there are two noteworthy reasons for this. (1) The incentive structure provides for and makes apparent actors' “encapsulated interests” (Hardin, 2001), because a valued good can only be produced collectively, and the risk of mutual deceit and nonadherence are minimal. Productive exchange is an internal solution to the enforcement problem because it creates a mutual- assurance game where actors' main challenge is to coordinate their behaviors to produce a collective good from which all receive their highest payoffs. Coordination is the major problem, not free riding. (2) Successful productive exchanges tend to foster a stronger sense of shared responsibility than other forms of social exchange (for supporting evidence, see Lawler, et al., 2008), and this strengthens the felt tie to the social unit (a relation or group). The person-to-unit tie enhances the degree that the relational tie among corrupt actors is set off from 
others in a larger network. This unique, shared relational tie addresses the enforcement problem internally, by affirming a group identity and fostering a collective orientation to the secrecy problem.

If corrupt behaviors take on the form of a productive exchange, however, they are more likely to be detected, especially in the long term. Productive exchanges mitigate the secrecy problem but leave behavioral traces of the collaboration that is involved in maintaining that secrecy. This is one reason that corrupt actors are often prosecuted for crimes ancillary to their core corrupt activities, for example, failure to pay taxes or violations of environmental regulation. Moreover, by demonstrating that the actors can work together, productive exchange encourages them to find new areas of corruption, through which they can jointly produce private gain, but it leads them to take risks that they otherwise would not take. All things being equal, broader and more expansive areas of corruption and pro-active efforts to maintain secrecy should foster even stronger person-to-group ties and enhance mutual dependencies, but at the expense of expanding the range of activities subject to detection.

To summarize, the following propositions extrapolate implications of how the forms of corrupt exchanges bear on the enforcement and detection problems facing the actors involved:

1. For corrupt exchanges, the likelihood of detection is lower in reciprocal forms of exchange than in negotiated or productive forms of exchange.

2. Reciprocal forms of corrupt exchanges evolve toward either (a) negotiated or (b) productive forms of exchange as actors reduce the risks of nonreciprocity and attempt to deal with the problem of secrecy. 
3. Negotiated forms of corrupt exchange reduce the risk of nonreciprocity without eliminating it, but increase the secrecy problem (risk of detection).

4. Productive forms of corrupt exchange both reduce the risk of nonreciprocity and mitigate the secrecy problem (the risk of detection) in the short term, without eliminating these problems in the long term.

5. The degree of trust (as “encapsulated interests”) produced by repeated corrupt exchange is ordered as follows: reciprocity $<$ negotiated $<$ productive.

6. The severity of the secrecy problem (risk of detection) for corrupt relations is ordered as follows: reciprocity $<$ productive $<$ negotiated.

Thus, the trust problem in reciprocal exchange leads to forms of corrupt exchange that may solve the "risk of non-reciprocity" but fail to satisfactorily solve the secrecy problem. Negotiated exchange enhances the detection problem, whereas productive exchange reduces it in the short, but not in the long, term. Because corrupt exchanges are embedded in a larger network, it is plausible that actors' ties to others in that network have a bearing on the capacity of A and B to successfully deal with the secrecy problem. The next section takes up this issue.

\section{Corrupt Exchange Networks and Detection}

A core principle of contemporary social exchange theory is that dyadic exchanges should be viewed in the context of the larger network within which they are embedded (see Emerson, 1972b). The underlying theoretical claim is that interactions in a dyad depend not just on the tie of the people in that dyad but also on the ties they have to others. The underlying empirical claim 
is that "isolated dyads" are rare and, if and when they develop, even these emanate from a larger set of network ties.

A network is defined as an opportunity structure, that is, a set of possible exchange partners available to one or both actors in a focal dyad. Patterns of exchange (who interacts with whom) generate a realized network within this set of possible ties (the opportunity structure). Minimally, an exchange network requires three actors, at least two of whom have potential ties. Since different network structures pose distinct secrecy challenges for actors engaged in corrupt exchanges, basic ideas about networks of exchange help us to further examine the problems of secrecy in corrupt exchanges.

Dyadic ties in exchange networks can be connected in different ways. The social exchange literature identifies three types of network connections (Emerson, 1972b; Willer, 1999): (1) exclusively connected exchanges, (2) inclusively connected exchanges, and (3) nullconnected exchanges. In a “'exclusively connected”' network, an exchange in one dyad excludes an exchange in another, so only a subset of the possible exchanges in a network actually occur. In an 'inclusive”' network, the benefits from a given tie requires all the others to be consummated as well; thus, a more dense set of network ties form and removal of any one (e.g., breaking secrecy) makes all ties vulnerable. In a “null”' network, there is no direct connection between ties, so few or many ties may occur depending on the actors. These network connections reflect different incentive structures for actors pursuing exchange with others.

Each type of network connection captures a different context of corruption and raises somewhat distinct secrecy or detection problems. Consider again the example of a government agent, who decides which contractor wins a bid to undertake a major construction project for the state. This describes a branch network that is exclusively or negatively connected. The agent (A) 
is the central actor with ties to many prospective contractors and only one of them can be chosen, and thus others have to be excluded. The contractors are in competition. They have an incentive to build a strong tie to or bribe the agent but those who lose the bid have an incentive to "rat out"' those who win with a bribe.

A fully connected, equal power network reveals similar dynamics. Here each actor can exchange with any of the other actors, but none are assured of an exchange. Consider a network of financial analysts who are willing to trade proprietary information to achieve market advantages. Each has an incentive to find a partner for corrupt exchanges of proprietary information, but those that do not find such partners have an incentive to report those that appear to. The competitive forces in a exclusively connected network make secrecy highly problematic for corrupt exchanges.

A plausible solution to these detection problems is to spread the contracts or information around over time such that many or all contractors receive contracts or all the financial analysts in a network receive valued private information. However, such arrangements are complicated and unstable. They involve explicit understandings among the entire set of actors in the network, which may solve the enforcement problem but will accentuate the secrecy problem. A single dissenting voice can unravel such an informal arrangement; moreover, it is difficult to maintain a parity or equality of benefits across individual actors, and those who are disadvantaged have an incentive to divulge the corruption to authorities. In some specific contexts, actors in the network develop norms and institutions that define corrupt practices (bribes, kickbacks, insider trading) as a standard, necessary business practice, something that is most likely in the context of a weak overarching legal framework as sometimes found at an international level or within developing 
countries (see Klitgaard, 1988). Our main point is that exclusively connected networks make it difficult for two parties engaged corruption to conceal it from peers.

A network is inclusive if all exchanges have to occur for any party to benefit. For example, in an inclusive network the central actor (C) receives benefits only if he or she interacts and exchanges with each of the other actors in a network. Whereas this central actor's payoffs are contingent on an exchange with only one actor in a exclusively connected network, C's payoffs are contingent on exchange with more than one actor in an inclusively connected network. The use of a middleman (C) for corrupt exchanges is an example.6 The tie between A and $\mathrm{C}$ and $\mathrm{C}$ and $\mathrm{B}$ enable $\mathrm{A}$ and $\mathrm{B}$ to maintain a separation between their corrupt giving behaviors, although the A-C and C-B ties have an explicit, negotiated form. This is exemplified by a lobbyist (C) who acts as an intermediary between a politician (A) and interest group (B) willing to purchase influence by contributing to A's campaign. The actors, A and B, can arrange an exchange of favors for contributions through the lobbyist (C). This ostensibly conceals the direct tie between A’s and B's exchange behavior.

Group-based corruption (e.g., organized or “enterprise”’ crime) is another example of an inclusive network. Here the benefits to each individual participant are contingent on their contributions, as well as those of others, to the collective enterprise. Inclusive networks are a structural foundation for productive forms of exchange. Shared interests in secrecy contribute to preserving it, but more actors are involved and, as noted earlier, people tend to undertake more risky varieties of corrupt behaviors under such conditions and develop more involved and detectable internal enforcement mechanisms to avert defection. With a middleman (C) both A and $\mathrm{B}$ are dependent on $\mathrm{C}$ and due to the problem of secrecy, $\mathrm{C}$ can play one side off against the 
other as the teritius gaudens. Thus, promised benefits, such as information, bribes, and gifts may not be assured.

In a null network there are neither positive nor negative connections between the exchange ties. Dyadic ties are connected through central or common nodes, positions, or actors in the network. Thus, an agent may benefit from exchanges with several others, but any given exchange or tie has no bearing on the agent's ties to others in the network. The actors in the network can treat their ties to others as distinct and independent. Consider a building or restaurant inspector who regularly inspects a group of buildings or restaurants and therefore has an ongoing tie with the managers of each of those units. The inspector can overlook violations, work to resolve them informally, or issue formal citations for violations, thereby imposing reputational and monetary costs on the building or restaurant. Bribes in exchange for "'going easy’” on a building or restaurant are difficult to detect as long as the inspector and manager keep the arrangement private. Thus, the secrecy problem is primarily internal to parties involved in the corrupt tie; the network establishes the basis for this. In null networks, the internal locus or source of the secrecy problem gives actors an incentive to make expectations for each other more explicit, but it also encourages them to develop a friendlier, more personal relationship that expands beyond the professional tie. The multidimensionality of the tie, however, may increase the likelihood of detection, in part because the inspector gains a “reputation” over time since building or restaurant managers are likely to have some ties with their counterparts.

The comparison of exclusive, inclusive, and null types of network configurations distinguishes different structural contexts for corruption and points to the structural sources of the secrecy problem. In a exclusively connected network, secrecy is problematic because of the competitive environment and incentives of those disadvantaged to reveal the corruption of 
others. In inclusive-networks, secrecy is problematic because more network ties are involved and thus there is greater potential for a weak link. Collaboration across many actors is more difficult to conceal from external sources. In null or unconnected networks, the secrecy problem is internal to a dyadic corrupt tie and a matter of whether the actors can trust each other to maintain secrecy, and this leads them to develop a larger social tie securing the corrupt exchange. In exclusive and inclusive networks, the threats to secrecy are external, whereas in null networks the threat is internal.

The solutions also differ across networks. There is no viable solution to the secrecy problem in a exclusively connected network, due to the competition for advantage. Reciprocal exchanges are unlikely to evolve toward negotiated exchanges in response to the enforcement problem because maintaining sufficient distance between A's and B's corrupt behavior is difficult. Corruption in competitive networks, where some have to be excluded, is fragile unless it is institutionalized. Inclusive networks introduce a group-basis for corruption by creating shared interests that can only be achieved in collaboration with others in the network. Middleman structures are inclusive, as are most instances of enterprise (organized) crime. Unlike the competitive incentives of exclusive networks, inclusive ones entail cooperative incentives and promote productive forms of corrupt exchange. Unconnected network ties (null) lead to separate dyadic ties, connected only indirectly through a common actor. Reciprocal corrupt behaviors in this context are likely to evolve toward more explicit, negotiated understandings of who does what and when, with informal agreements to maintain secrecy.

To summarize, several propositions are implied by the above discussion: 
1. In exclusively connected exchange networks, corrupt exchanges remain reciprocal in form with little evolution toward either negotiated or productive forms, because the competitive context enhances the threats to secrecy.

2. In inclusively connected exchange networks, corrupt exchanges become productive in form, because actors’ mutual dependence and shared interests in collaboration mitigate threats to secrecy. However, they increase the enforcement problem due to the prospects of malfeasance by the central actor in the network or " whistle blowing', by one of the peripheral actors.

3. In unconnected (null) exchange networks, corrupt exchanges become negotiated in form, because their mutual dependence enhances trust and they face only internal sources of secrecy.

Overall, social exchange theory has important implications for understanding how corrupt exchanges change ongoing relational ties. First of all, a corrupt exchange in a legitimate relation increases mutual dependence by creating a new joint good (secrecy) that actors have an incentive to produce and that also sets their relationship apart from many others they are involved in. Second, concomitant with this secrecy problem is an enforcement problem, that is, how trust can be assured in the absence of readily available third parties that are typically present for legitimate, normatively sanctioned relations. Third, in acting to solve these dual problems detection and enforcement - actors tend to expand or change the domains of their interaction or exchange and thereby create new areas where detection or enforcement are problematic; that is, they make themselves more vulnerable. In this sense, social exchange theory suggests how 
corrupt relations evolve over time and implies that they incorporate the seeds of their own destruction.

\section{CONCLUSIONS}

This chapter conceives of corruption as social exchange, involving two or more actors. The opportunity for corrupt exchange stems from an already- existing social tie. This could be a professional tie such as that between a politician and contributor, a building inspector and building manager, or a government procurement officer and vendor. This social-grounding or embeddedness of corrupt exchanges enables actors to secure their corrupt exchange, that is, come to trust each other to provide the benefits expected and maintain the necessary secrecy.

There are two fundamental problems of corrupt exchanges that make such relationships unstable. First, there are no legitimate “third party enforcement” mechanisms that can be accessed if a party does not fulfill her or his side of the bargain. The parties themselves have to secure the exchange. Second, given the corrupt exchange is illegitimate or illicit, there is pressure on parties to carefully maintain the secrecy of their corrupt exchanges. Again, this is a task they have to resolve themselves without outside assistance. The need for secrecy not only makes it important for them to understand each other's commitment to secrecy but also each other’s willingness and competence to accomplish it repeatedly over time.

How can corrupt relationships build stability despite no external enforcement mechanisms? The answer offered in this chapter involves two main points. (1) Corrupt exchanges increase each actor's dependence on the other, making them more mutually dependent, but also more vulnerable to each other. In legitimate exchange relations, increases in 
mutual dependence strengthen relational ties by “'encapsulating”’ actors’ interests, promoting positive affective ties, and the like. In illegitimate or corrupt relations, we argue that these effects are countervailed by problems of detection and enforcement. The key reason is that a new joint good emerges - the need for secrecy - when people engage in a corrupt exchange. They have and know they have a shared interest in collaborating to generate this good; yet, the more they collaborate to produce it the more vulnerable they become to each other and to detection from the outside. The mutual dependence of corrupt actors increases their incentives to deal with the secrecy problem, but it remains a pervasive, unresolvable source of uncertainty about each other. (2) People can reduce uncertainty about each other by demonstrating or affirming their commitment to their exchange and their relationship. Reciprocal exchanges that maintain a sharp separation between giving behaviors may evolve toward more explicit, negotiated forms of corrupt exchange where understandings of who does what are clearer, or toward collaborative efforts that are organized around the secrecy problem and generate productive forms of corrupt exchange.

Given these stabilizing factors, why are corrupt exchanges likely to be eventually revealed? Under normal exchange conditions, adding a new type of exchange to an existing relation strengthens the relationship and makes the larger tie more cohesive, but in the case of a corrupt exchange, we argue that such effects are likely to be short term. The reason is that a pattern of corrupt exchanges unleashes endogenous processes that are a threat to the larger relationship. In the case of corrupt relations, negotiated and productive exchanges entail greater detection problems. By seeking to hide their connections, parties to corruption integrate further ties into the corrupt exchange. This way, however, the problem of secrecy and detection, is only solved for the short but not the long run. The overall implication is that corrupt exchanges face a 
dilemma that actors cannot solve. All the ways through which parties seek to deal with the problems of enforcement and detection inherently constitute the "seeds" of relational destruction.

To conclude, corruption can be construed as a special class of social exchange. It has three distinct properties: (a) it is normatively illegitimate in the context; (b) it generates negative externalities for a third party (e.g., the community or public); and (c) secrecy is a joint good that is necessary for parties to receive the benefits from corrupt exchange. The problems that we have identified with corrupt exchanges apply to other types of illicit relationships, such as extramarital affairs and secret organizations; such relations entail enforcement and detection problems that are difficult for actors to resolve without creating new layers or problems of secrecy. Any solution is temporary or tenuous; any solution also requires clearer demonstrations of reliability and commitment by each party, resulting in new points of uncertainty for each. 


\section{Notes}

1. Transaction-cost theory points to the costs of corrupt actors finding reliable (and corrupt) exchange partners, with whom they can be confident of the secrecy of the transaction. The main idea is that a unique feature of corrupt exchanges is that they cannot rely on any external enforcement mechanism. This is generally consistent with implications of a social exchange approach.

2. Principal-agent theory addresses the incentives that initially lead to corrupt exchanges and how patterns of corruption develop given those incentives. Social exchange theory can address the initial incentives and development of repetitive patterns as well, but we suggest that its major contribution is to offer a unique way of understanding what happens to an ongoing exchange relation when a corrupt exchange occurs.

3. Generalized exchange is a fourth form of exchange. It is indirect, that is, there is no direct connection between a given pair of actors (A and B). Although collective or enterprise corruption (e.g., organized crime syndicates) can involve elements of generalized exchange, this form is not included in our analysis. To deal with the problems of detection and enforcement, strong social institutions or a common group affiliation between givers and receivers would be necessary in a corrupt generalized exchange context.

4. Resources or behavioral capabilities, that actors within an exchange relationship value can either fall in the same or different exchange domains (Emerson, 1972a). The contractor, for example, values exclusive information about a bid, whereas the government official is interested in new job opportunities or financial rewards (different exchange domains). Two financial analysts, in contrast, may both value exclusive information (same exchange domain). 
5. Negotiated and reciprocal exchanges involve a mixed motive setting in which actors have incentives to cooperate and defect (give and not give). In their purest forms (see Molm, 2003a; Molm, Schaefer, \& Collett, 2007), negotiated exchange makes the diverging interests more salient to actors than reciprocal exchange, and this makes it easier for people in reciprocal exchange to develop cohesive relations. We assert that the secrecy problem of corrupt exchanges actually reverse these patterns - specifically, more explicit exchanges are a stronger foundation for cohesive relations than less explicit, reciprocal forms.

6. What we consider a middleman in the context of a corrupt exchange is essentially what Corra and Willer (2002) define as a “gatekeeper”. A gatekeeper controls the access to resources valued by others but does not own them. In the above example, the lobbyist controls the access to a politician but cannot ensure changes to legislation. 


\section{References}

Ashforth, B. E., \& Anand, V. (Eds). (2003). The normalization of corruption in organizations (Vol. 25). New York: Elsevier.

Ashforth, B. E., Gioia, D. A., Robinson, S. L., \& Trevino, L. K. (2008). Re-viewing organizational corruption. Academy of Management Review, 33(3), 670-684.

Azfar, O., Lee, Y., \& Swamy, A. (2001). The causes and consequences of corruption. ANNALS Of the American Academy of Political and Social Science, 573(1), 42-56.

Bacharach, S. B., \& Lawler, E. J. (1981). Bargaining: Power, tactics and outcomes. San Francisco, CA: Jossey-Bass.

Bacharach, S. B., \& Lawler, E. J. (1998). Political alignments in organizations: Contextualization, mobilization, and coordination. In: R.M. Kramer \& M.A. Neale (Eds), Power and influence in organizations (pp.67-88). Thousand Oaks, CA: Sage.

Banfield, E. C. (1958). The moral basis of a backward society. Glencoe, IL: Chicago Free Press; Research Center in Economic Development and Cultural Change, University of Chicago.

Cohen, J. R., Pant, L. W., \& Sharp, D. J. (1996). A methodological note on cross-cultural accounting ethics research. The International Journal of Accounting, 31(1), 55-66.

Cook, K. S., Hardin, R., \& Levi, M. (2005). Cooperation without trust? New York: Russell Sage Foundation.

Corra, M., \& Willer, D. (2002). The gatekeeper. Sociological Theory, 20(2), 180-207.

Della Porta, D., \& Meny, Y. (1997). Democracy and corruption in Europe. London: Washington. 
Della Porta, D., \& Rose-Ackerman, S. (2002). Corrupt exchanges: Empirical themes in the politics and political economy of corruption. Baden-Baden: Nomos.

Della Porta, D., \& Vannucci, A. (1999). Corrupt exchanges: Actors, resources, and mechanisms of political corruption. New York: Aldine de Gruyter.

Della Porta, D., \& Vannucci, A. (2005). The governance mechanisms of corrupt transactions. In: J. G. Lambsdorff, M. Taube \& M. Schramm (Eds), The new institutional economics of corruption (pp. 152-177). New York: Routledge.

Emerson, R. M. (1972a). Exchange theory, part I: A psychological basis for social exchange: Exchange rules and networks. In: J. Berger, M. J. Zelditch \& B. Anderson (Eds), Sociological theories in progress (pp. 38-57). Boston: Houghton-Mifflin.

Emerson, R. M. (1972b). Exchange theory, part II: Exchange rules and networks. In: J. Berger, M. J. Zelditch \& B. Anderson (Eds), Sociological theories in progress (pp. 58-87). Boston: Houghton-Mifflin.

Emerson, R. M. (1981). Social exchange theory. In: M. Rosenberg \& R. H. Turner (Eds), Social psychology: Sociological perspectives (pp. 30-65). New York: Basic Books, Inc.

Granovetter, M. (2007). The social construction of corruption. In: V. Nee \& R. Swedberg (Eds), On capitalism (pp. 152-172). Palo Alto, CA: Stanford University Press.

Hardin, R. (2001). Conceptions and explanations of trust. In: K. S. Cook (Ed.), Trust in society (Vol. 2, pp. 3-39). New York: Russell Sage Foundation.

Heidenheimer, A. J., \& Johnston, M. (2001). Political corruption: Concepts and context. New Brunswick, NJ: Transaction Publishers.

Husted, B. W. (1999). Wealth, culture, and corruption. Journal of International Business Studies, 30(2), 339-359. 
Klitgaard, R. E. (1988). Controlling corruption. Berkeley, CA: University of California Press.

Kollock, P. (1994). The emergence of exchange structures - An experimental-study of uncertainty, commitment, and trust. American Journal of Sociology, 100(2), 313-345.

Lambsdorff, J. G. (2002a). How confidence facilitates illegal transactions: An empirical approach. The American Journal of Economics and Sociology, 61(4), 829.

Lambsdorff, J. G. (2002b). What nurtures corrupt deals? On the role of confidence and transaction costs. In: D. Della Porta \& S. Rose-Ackerman (Eds), Corrupt exchanges: Empirical themes in the politics and political economy of corruption (pp. 20-35). BadenBaden: Nomos.

Lambsdorff, J. G., Taube, M., \& Schramm, M. (Eds). (2005). The new institutional economics of corruption (Vol. 64). London: Routledge.

Lawler, E. J. (1992). Power processes in bargaining. The Sociological Quarterly, 33(1), 17-34.

Lawler, E. J. (2001). An affect theory of social exchange. American Journal of Sociology, 107(2), 321-352.

Lawler, E. J. (2006). Exchange, affect, and group relations. In: A. J. Trevino (Ed.), George C. Homans: History, Theory, and Method (pp. 177-202). Boulder, CO: Paradigm Publishers.

Lawler, E. J., \& Thye, S. R. (2006). Exchange theory of emotion. In: J. Stets \& J. Turner (Eds) Handbook of the sociology of emotions. New York: Springerforthcoming.

Lawler, E. J., Thye, S., \& Yoon, J. (2009). Social commitments in a depersonalized world. New York: Russell Sage.

Lawler, E. J., Thye, S. R., \& Yoon, J. (2008). Social exchange and micro social order. American Sociological Review, 73(4), 519-542. 
Lawler, E. J., \& Yoon, J. (1993). Power and the emergence of commitment behavior in negotiated exchange. American Sociological Review, 58(4), 465-481.

Lawler, E. J., \& Yoon, J. (1996). Commitment in exchange relations: Test of a theory of relational cohesion. American Sociological Review, 61(1), 89-108.

Lawler, E. J., \& Yoon, J. (1998). Network Structure and emotion in exchange relations. American Sociological Review, 63(6), 871-894.

Molm, L. D. (1987). Extending power dependency theory: Power processes and negative outcomes. In: E. J. Lawler \& B. Markovsky (Eds), Advances in group processes (Vol. 4, pp. 178-198). Greenwich, CT: JAI Press.

Molm, L. D. (1994). Dependence and risk: Transforming the structure of social exchange. Social Psychology Quarterly, 57(3), 163-176.

Molm, L. D. (2003a). Power, trust, and fairness: Comparisons of negotiated and reciprocal exchange. In: S.R. Thye \& J. Skvoretz (Eds), Power and status (Vol. 20, pp. 31-66). Oxford: Elsevier.

Molm, L. D. (2003b). Theoretical comparisons of forms of exchange. Sociological Theory, 21(1), 1-17.

Molm, L. D., \& Cook, K. S. (1995). Social exchange and exchange networks. In: K. S. Cook, G. A. Fine \& J. S. House (Eds), Sociological perspectives on social psychology (pp. 209235). Boston: Allyn and Bacon.

Molm, L. D., Peterson, G., \& Takahashi, N. (1999). Power in negotiated and reciprocal exchange. American Sociological Review, 64(6), 876-890.

Molm, L. D., Schaefer, D. R., \& Collett, J. L. (2007). The value of reciprocity. Social Psychology Quarterly, 70(2), 199-218. 
Molm, L. D., Schaefer, D. R., \& Collett, J. L. (2009). Fragile and resilient trust: Risk and uncertainty in negotiated and reciprocal exchange. Sociological Theory, 27(1), 1-32.

Rose-Ackerman, S. (1999). Corruptions and government-causes, consequences, and reform. New York: Cambridge University Press.

TDM/Transnational Dispute Management. (2006). World Duty Free Company Limited (Claimant) v. the Republic of Kenya (Respondent) (ICSIC Case No. Arb/00.07). Transnational Dispute Management.

Thye, S. R., Yoon, J., \& Lawler, E. J. (2002). The theory of relational cohesion: Review of a research program. In: S. R. Thye \& E. J. Lawler (Eds), Advances in group process (Vol. 19, pp. 139-166). Oxford: Elsevier.

Transparency International. (2008). Global corruption report. Cambridge, UK: Cambridge University Press.

Willer, D. E. (1999). Network exchange theory. Westport, CT: Praeger Publisher. 